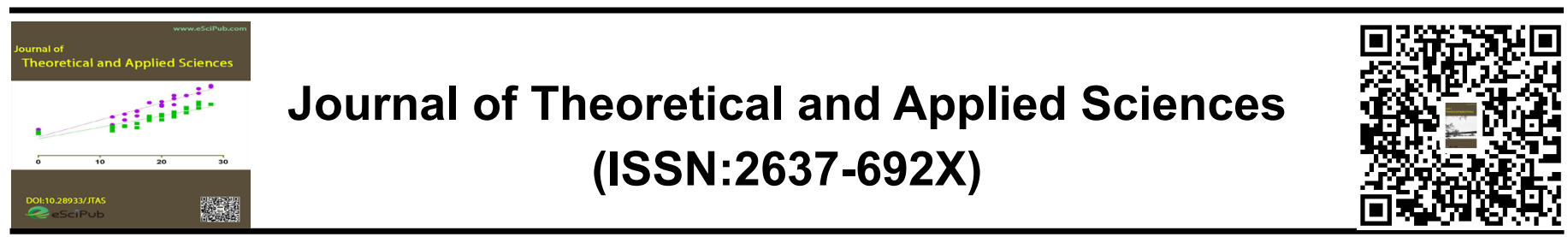

\title{
Preparation and modification of nanometer zero-valent iron
}

\author{
Chao Hu, QiangFu Wei, JiaQi Ju, Bo Wang, Ying Wang, HeYing Chen
}

College of Ocean Science and Engineering, Shanghai Maritime University, Shanghai 201306, China.

\begin{abstract}
Nanometer zero-valent iron ( $\mathrm{nZVI}$ ) technology is one of the hotspot in environmental science, according to its huge surface area and high reactivity for the heavy metals, halogenated organic matter. However, as a result of a single $\mathrm{nZVI}$ problems easy to reunite and oxidized effect of $n Z V I$ reactivity, reduction of pollutant removal effect, the modification of nanometer zerovalent iron is a hotspot of $\mathrm{nZVI}$ technology this paper mainly discusses the conventional physical and chemical preparation methods of nanometer zero-valent iron and modified nano zerovalent iron technology are summarized, the future research emphases of $\mathrm{nZVI}$ technology are prospected.
\end{abstract}

Key words: nZVI preparation method modification
*Correspondence to Author:

Chao $\mathrm{Hu}$

College of Ocean Science and Engineering, Shanghai Maritime University, Shanghai 201306, China.

How to cite this article:

Chao Hu, QiangFu Wei, JiaQi Ju, Bo-Wang, Ying Wang, HeYing Chen. Preparation and modification of nanometer zero-valent iron.Journal of Theoretical and Applied Sciences, 2019, 2:12

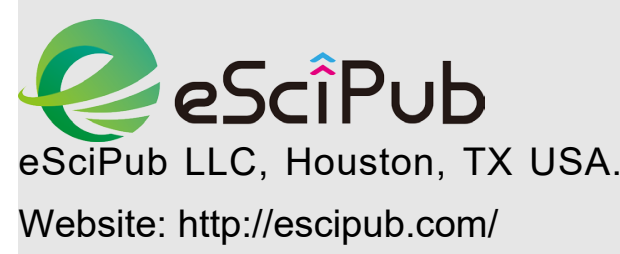




\section{Introduction}

Nanometer zero-valent iron (nZVI) is a zero-valent iron particle with particle size between 1 $100 \mathrm{~nm}$. It is widely used in sewage treatment and has obvious effects on the removal of organic chloride, inorganic anions, heavy metals, organic dyes and pesticides in water bodies. Compared with traditional materials, nanometer zero-valent iron has smaller particle size, larger specific surface area, good adsorption and strong reactivity. The unique advantages of nano-zero-valent iron have good application prospects in the treatment of environmental pollutants such as groundwater remediation. In recent years, more and more attention has been paid to the preparation process, microstructure and performance characterization of nano-metallic iron materials, and many new progresses have been made ${ }^{[1]}$. Nano technology provides a new research opportunity for environmental security domain, especially nanometer zero-valent iron to promote the development of environmental pollution restoration research. The preparation and modification technology research of nZVI, and future research direction of this technique are proposed in this paper.

\section{Preparation of nanometer zero-valent iron} The preparation method of nanometer zero-valent iron has a direct influence on the quality of nanometer zero-valent iron and its feasibility in industrial mass production ${ }^{[2]}$. According to the different properties of preparation methods of nanometer zero-valent iron, the preparation methods of nanometer zero-valent iron can be divided into physical method and chemical method.

\subsection{Physical preparation of nanometer zero- valent iron}

(1) High Energy Mechanical Ball Milling. At present, this method is one of the most commonly used physical methods for the preparation of nano-zero-valent iron. Metal powder is placed in a high-energy mechanical ball mill for a long time to operate. With the help of the rotation of the high-energy ball mill, the media and materials are repeatedly squeezed and ground in the state of condensation, so that the deformation and fracture of material particles can be diffused into ultra-fine particles ${ }^{[3]}$. This method is simple in operation, low in cost and high in yield. It is suitable for industrial mass production of nZVI. However, impurities are easy to be introduced in the preparation process.

(2) Vapour deposition method. Vacuum evaporation laser heating evaporating electron beam irradiation sputtering and other methods are used to gasify or form plasma of raw materials, and precipitous condensation in the medium. The nanometer zero-valent iron prepared by this method has small particle size, high purity and even dispersion, but the preparation cost is high and the equipment requirements are high, so it is generally not suitable for mass production $^{[4]}$.

(3) Freeze-drying method. Spray freeze drying is to put the metal salt water solution to low temperature environment to make quick frozen water, and then under the condition of low temperature vacuum sublimation, dehydration can be obtained after heating metal oxide superfine powder made of powder particle size small high purity and good uniformity, this me- thod can also be mass produced particles, and lower $\operatorname{cost}^{[5]}$.

\subsection{Chemical preparation of nanometer zer- o-valent iron}

(1) Liquid phase reduction method. This metho$\mathrm{d}$ is currently the most commonly used method for preparing nano-zero-valent iron in laboratory. In liquid phase, nano-zero-valent iron was prepared by reducing iron salts with sodium borohydride and other reducing agents through reaction equations (1), (2). Chen ${ }^{[6]}$ et al. used liquid phase reduction method to reduce $\mathrm{FeSO}_{4}$ solution with $\mathrm{NaBH}_{4}$. The particle size of $\mathrm{nZVI}$ prepared by this method ranged from 50 to 100 $\mathrm{nm}$. The $\mathrm{nZVI}$ obtained by this method was used to treat wastewater containing $\mathrm{Pb}^{2+}$. The results showed that when the amount of $\mathrm{nZVI}$ was $1 \mathrm{~g} / \mathrm{L}$ and the initial concentration of $\mathrm{Pb}^{2+}$ was 50 and $100 \mathrm{mg} / \mathrm{L}$, the removal rate of $\mathrm{Pb}^{2+}$ was over $99 \%$ after 120 minutes of equilibrium 
reaction.

$4 \mathrm{Fe}^{3+}+3 \mathrm{BH}_{4}{ }^{-}+9 \mathrm{H}_{2} \mathrm{O} \rightarrow 4 \mathrm{Fe}^{0}(\mathrm{~s})+3 \mathrm{H}_{2} \mathrm{BO}_{3}{ }^{-}+12 \mathrm{H}^{+}+$

$6 \mathrm{H}_{2}(\mathrm{~g})$

$\mathrm{Fe}^{2+}+3 \mathrm{BH}_{4}{ }^{-}+6 \mathrm{H}_{2} \mathrm{O} \rightarrow \mathrm{Fe}^{0}(\mathrm{~s})+2 \mathrm{~B}(\mathrm{OH})_{3}+7 \mathrm{H}_{2}(\mathrm{~g})$

(2) Pyrolysis of iron carbonyl. Nano-zero-valent iron was prepared by means of activation such as pyrolysis and ultrasound (equation (3)). By this method, zero-valent iron of very fine nanometer size can be produced, Feng ${ }^{[7]}$ et al. used this method to prepare $\mathrm{nZVI}$, particle size is $30-40 \mathrm{~nm}$, and studied the degradation mechanism of $\mathrm{nZVI}$ to 2,4-dichlorophenol. It was found that the removal rate of $\mathrm{nZVI}$ to chlorophenol increased with the lowing of $\mathrm{pH}$ value. Acidic conditions were conducive to improving the reduction degradation rate of chlorophenol. Especially $\mathrm{pH}=3$, the removal rate of chlorophenol could reach more than $90 \%$ within 24 hours. In acidic system, the oxidation and agglomeration of nano-zero-valent iron have been alleviated. Although it may cause a part of iron loss, the reaction produces a large number of ferrous ions and promotes dechlorination and degradation.

$\mathrm{Fe}(\mathrm{CO})_{5} \rightarrow \mathrm{Fe}(\mathrm{s})+5 \mathrm{Co}(\mathrm{g})$

(3) Electrochemistry deposition. In an electric field, the deposition of metal or metal compounds from the aqueous solutions of their compounds, non-aqueous solutions or molten salts to the electrode surface. In the preparation of nano-materials, this method is mainly used to prepare nano-zero-valent iron particles. The method has low cost and is suitable for large-scale production. Zhou ${ }^{[8]}$ et al. Used electrodeposition to electroplate nanocrystalline zero valent iron on the surface of granular activated carbon, and preliminarily discussed the removal effect of nano zero valent iron / activated carbon composite adsorbent on simulated groundwater As (III). The results showed that the removal rate of As (III) exceeded $90 \%$ when the concentration of As (III) was $2 \mathrm{mg} / \mathrm{L}$, the dosage of adsorbent was $7 \mathrm{~g} / \mathrm{L}$ and the adsorption lasted for 1 hour. The preparation of nano-zero-valent iron by electrochemical deposition is low-cost a- nd has great potential in engineering applications.

\section{Modification of nanometer zero-valent ir- on}

Nanoscale zero valent iron has small particle size and high reactivity, and is widely used in environmental applications. However, because $\mathrm{nZVI}$ is easy to agglomerate and oxidize, it is very limited in wastewater treatment, so it is necessary to modify $\mathrm{nZVI}$ to improve the removal efficiency of pollutants in the environment.

\subsection{Nano zero valent iron bimetal}

Research shows that the degradation efficiency could be effectively improved by loading another metal on the surface of nano-zero-valent iron. Supporting nano-zero-valent iron particles on solid carriers can increase the specific surface area of nanoparticles, inhibit agglomeration, or wrap polymer electrolytes or surfactants on the surface of nano-zero-valent iron particles. Through steric hindrance or electrostatic repulsion, agglomeration degree of nanoparticles can be effectively reduced, and fluidity of nano-zero-valent iron particles in water or soil can be enhanced ${ }^{[9]}$.

Zhou ${ }^{[10]}$ et al. studied the degradation of trichloroethylene (TCE) by nano-iron-nickel bimetal coated with chitosan. It was found that nano-iron-nickel bimetal coated with chitosan improve$\mathrm{d}$ the oxidative agglomeration, inactivation and poor mobility of nano-zero-valent iron. Iron-nickel bimetals constitute the primary battery system, which accelerates the corrosion of Fe. Hydrogen generated by iron corrosion is adsorbed on nickel metal on the surface of iron. Active hydrogen is easily formed by nickel metal catalysis. This form has high reducibility, improve$s$ the efficiency of reductive dechlorination, and achieves TCE complete dechlorination.

$\mathrm{Fu}^{[11]}$ et al. explored the effect of nanoscale zero valent iron copper bimetallic on the removal rate of four chloro bisphenol A (TCBPA). The effects of initial concentration of TCBPA, dosage of $\mathrm{Cu} / \mathrm{nZVI}, \mathrm{pH}$ and temperature on degradation rate of TCBPA in soil were studied. The results of batch experiments showed that the degradation rate of $0.30 \mathrm{~g} \mathrm{Cu} / \mathrm{nZVI}$ to 0.8 
$\mathrm{mg} \mathrm{g}^{-1}$ TCBPA in soil could reach more than 85 $\%$ when system reaction temperature at $25^{\circ} \mathrm{C}$ and in $360 \mathrm{~min}$ reaction. The degradation rate of TCBPA in soil by $\mathrm{Cu} / \mathrm{nZVI}$ decreased with the increase of initial concentration of TCBPA, increased with the increase of $\mathrm{Cu} / \mathrm{nZVI}$ dosage, and decreased with the increase of initial soil $\mathrm{pH}$. GC-MS results showed that degradation of TCBPA by $\mathrm{Cu} / \mathrm{n} \mathrm{ZVI}$ was a progressive dechlorination process.

\subsection{Solid load}

Loading technology generally loads the generated $\mathrm{nZVI}$ particles onto the solid carrier, which can reduce the $n Z V I$ reunion, enhance its migration ability in the environment, and is conducive to the restoration of the environment. At the same time, natural and synthetic solid carriers have strong adsorption capacity, such as activated carbon and silica, which can adsorb pollutants in water on the surface of particles, thus speeding up the reaction rate. Supporting $\mathrm{nZVI}$ on organic bentonite, carbon, silicon and resin to avoid the oxidative agglomeration of $\mathrm{nZVI}$ and to improve the reactivity and efficienc$y$ are the research hotspots of nZVI technology at present.

$\mathrm{Liu}^{[12]}$ et al. studied the removal efficiency of $U$ (VI) in aqueous solution by using activated carbon supported nano-zero-valent iron. The resuIts showed that nano-zero-valent iron load- ed on activated carbon had a good removal effect on $\mathrm{U}(\mathrm{VI})$. When the solution $\mathrm{pH}=5$, the dosage of adsorbent was $5 \mathrm{mg}$, the initial mass concentration of $\mathrm{U}(\mathrm{VI})$ was $250 \mathrm{mg} / \mathrm{L}$, the reaction temperature was $35^{\circ} \mathrm{C}$, and the adsorption time about $60 \mathrm{~min}$, the removal rate of $U$ (VI) by nano-zero-valent iron loaded on activated carbon was $98.52 \%$. Moreover, the kinetics of uranium adsorption by activated carbon supported nano-zero-valent iron conforms to the quasi-second-order kinetics model.

Wang ${ }^{[13]}$ successfully loaded S-nZVI with bentonite, and explored the removal effect of bentonite loaded S-nZVI on nitrophenol (PNP). The effects of $n Z V I$ loading rate, dosage of composite materials and $\mathrm{pH}$ on PNP removal rate were studied. When the $\mathrm{nZVI}$ loading rate is $50 \%$, the removal rate of PNP is the largest. When the dosage of composite material was $0.5 \mathrm{~g} / \mathrm{L}$, the solubility of $\mathrm{PNP}=1.5 \mathrm{mM}, \mathrm{pH}=5$, the removal rate of PNP in $10 \mathrm{~min}$ is close to
100\%. Experiments show that bentonite-loaded S-nZVI material has the characteristics of fast removal rate and high efficiency of PNP.

\section{Prospect}

(1) The preparation and modification technology of nano-zero-valent iron has been mature in the laboratory stage, and the removal effect of halogenated organic compounds is very good for heavy metals. However, the high cost of preparation of nano-zero-valent iron limits its application in practical engineering. Therefore, we should find more effective preparation methods of nano-zero-valent iron, reduce the cost of preparation of nano-zero-valent iron, and increase the application of nano-zero-valent iron in practical engineering.

(2) Nano-zero-valent iron technology can only be used to treat simulated wastewater in the laboratory stage. There are few experimental studies on actual wastewater or mixed wastewater. It is necessary to strengthen the researc$\mathrm{h}$ of nano-zero-valent iron on the treatment of actual wastewater.

(3) It is necessary to explore the impact of nanoscale zero valent iron injected into the environment on the ecology and biological pathology.

\section{References}

1. Wang, X., Ding, QW., Liu, HF. et al. Preparation and characterization of nano-iron with different dispersants[J]. Journal of Taiyuan University of Science and Technology. 2010, 31 (05): 432-5.

2. Zhang, W., Shen, Z., Wang, CL. et al. Modification of nanometer zero-valent iron and its application in wastewater treatment[J]. Water purification technology. 2016, 35 (04): 23-30.

3. Li, S., Yan, W., Zhang, WX. et al. Solvent-free production of nanoscale zero-valent iron (nZVI) with precision milling[J]. Green Chemistry.2009, $11(10)$.

4. Zhang, XX., Xia, XF., Zhou, W. et al. Progress in preparation of nano-sized zero-valent iron and its application in the environment[J]. Environmental Science and Technology. 2016, 39 (01): 60-5.

5. Zhang, JC., Liu, G., Cao, WL. et al. Character- 
Chao Hu et al.,JTAS, 2019; 2:12

istics, applications and preparation methods of nanoparticles[J]. Journal of Petrochemical Colleges and Universities. 2001 (02): 21-6.

6. Chen, Y., Zhu, J., Wang, P. Preparation of nano-zero-valent iron by liquid phase reduction and its removal of $\mathrm{Pb} 2+$ from water[J]. China Powder Technology. 2017, 23 (01): 1-6.

7. Feng, L., Ge, XP. Wang, DS. et al. The effect of $\mathrm{pH}$ value on the adsorption and degradation of 2,4-dichlorophenol by nano-zerovalent iron[J]. Environmental Science. 2012, 33 (01): 94-103.

8. Zhou, JJ., Li, ZJ. Preparation of activated carbon/nano-zero-valent iron composite adsorbent and its application in arsenic removal[J]. Environmental Science and Management. 2012, 37 (10): 106-8.

9. Pang, L., Zhou, QX., Su, XF. et al. Progress in nano-scale zero-valent iron modification[J]. Chemical progress. 2011, 30 (06): 1361-8.

10. Zhou, XY., Li, Z., Chen, JW. et al. Migration properties of nano-iron-nickel bimetallic coated with chitosan and its degradation of trichloroethylene in groundwater[J]. Modern Geology. 2018, 32 (06): 1322-8.

11. Fu, X., Liang, L., Li, XQ. et al. Degradation of tetrachlorobisphenol $\mathrm{A}$ in soil by nano-zero-valent iron-copper bimetallic system[J]. Journal of Environmental Sciences. 2018, 38 (04): 1606-12.

12. Liu, DQ., Liu, SR., Wang, CF. et al. Study on removal of $\mathrm{U}(\mathrm{VI})$ from aqueous solution by nano-zerovalent iron loaded with activated carbon[J]. Journal of IOL. 2016, 45 (05):132834.

13. Wang YH. Preparation of nano-sized zero-valent iron sulfided on bentonite and its removal of p-nitrophenol in water[D]. Shandong University. 2018. 